\title{
Implementasi Keputusan Munas Tarjih tentang Zakat Profesi pada Amal Usaha Muhammadiyah di Kota Pontianak
}

\author{
Wagiyem \\ Email: marsamwamar@gmail.com
}

\begin{abstract}
This study examines the implementation of the Munas Tajih Decree on theprofessionzakat of the Muhammadiyah charity in Pontianak City. This study is classified as field research with resource from Muhammadiyah Regional Board of West Kalimantan, Muhammadiyah Regional Executive of Pontianak City, Head of Muhammadiyah Business Charity in Pontianak City, and Amil Zakat Institution Board. The result of this study is that the Muhammadiyah Regional Policy of West Kalimantan / Derah Pontianak is to continue the policy of employee salary deduction in charitable efforts of Muhammadiyah as zakat, infak and shadaqah (zis), issuing instructions to fund zis collected by AUM disetited to Lazismu. The management of zis ah in AUM in Pontianak City varies and develops from time to time. Some are internally distributed, some are initially distributed internally but are subsequently distributed externally. Since the instruction of the Muhammadiyah Regional Leadership of West Kalimantan, most AUM have deposited zakat, infaq and shadaqah to the distributed Lazismu for urgent needs and productive activities in accordance with the guidelines issued by the Muhammadiyah Central Executive. In general, there are no obstacles faced in the implementation of the Munas Tarjih decision on the Muhammadiyah business charity in the city.
\end{abstract}

Keywords: zakat profesi, tarjih, Muhammadiyah charity efforts.

\section{Pendahuluan}

Muhammadiyah dikenal sebagai organisasi yang dasar dan haluannya bersendikan ajaran Islam dan bertujuan untuk meningkatkan kehidupan kaum muslimin dengan misi utamanya adalah melakukan pembaharuan kehidupan keagamaan dan sosial dengan memberikan pemecahan terhadap masalah-masalah agama dengan selalu 
mengembalikannya pada tuntutan Alquran dan Sunnah Rasul sehingga organisasi ini dijuluki sebagai gerakan tajdid. Untuk keperluan itu ulama-ulama Muhammadiyah sejak semula senantiasa melakukan kegiatan tarjih. Bahkan K.H. Ahmad Dahlan selaku pendiri Muhammadiyah pun telah melakukannya sebagaimana tampak dalam keputusannya tentang penentuan arah kiblat dan cara penentuan hari raya. Menyadari semakin besarnya tuntutan terhadap Muhammadiyah untuk melakukan kegiatan tarjih maka pada tahun 1928, dalam Kongres ke-17 di Yogyakarta dibentuk Majelis Tarjih (Anis 1972).

Salah satu masalah kontemporer yang menjadi perhatian Majelis Tarjih adalah zakat profesi. Masalah ini dibahas pada Muktamar Tarjih Muhammadiyah ke-22 di Malang tahun 1989. Pembahasan topik ini sesuai dengan realitas perkembangan kehidupan masyarakat modern yang dalam hal pekerjaan tidak terbatas pada pekerjaan konvensional seperti sebagai petani, peternak, atau pedagang sebagaimana yang dikenal pada masa dahulu. Para pekerja profesional seperti dokter, dosen, guru, akuntan, konsultan, notaris, insinyur dan pekerja seni banyak yang memiliki penghasilan yang cukup besar, bahkan jauh lebih besar bila dibandingkan dengan penghasilan seorang petani (Pimpinan Pusat Muhammadiyah 1990).

Dalam arena Muktamar Tarjih kali ini muncul dua pendapat tentang hukum zakat profesi. Satu kelompok sepakat bahwa zakat profesi hukumnya wajib sementara satu kelompok lainnya berpendapat sebaliknya. Meskipun sebagian besar muktamirin berpendapat bahwa zakat profesi wajib, tetapi masalah tersebut belum dapat diselesaikan. Maka dari itu, sidang memutuskan menyerahkan kepada PP Muhammadiyah Majelis Tarjih. Hasil-hasil pemahaman pihak yang mengakui adanya wajib zakat profesi dan pihak yang menolaknya untuk dijadikan kajian lebih lanjut.

Masalah zakat profesi baru diangkat kembali pada Munas Tarjih ke-25 di Jakarta bulan Juli 2000. Dalam munas ini keputusan yang diambil pada Muktamar Tarjih ke-22 dijadikan bahan kajian utama ditambah dengan kertas kerja yang disajikan oleh Majelis Tarjih dan Pengembangan Pemikiran Islam Jawa Timur. Munas ini akhirnya menyepakati tentang wajibnya hukum zakat profesi.

Keputusan Munas Tarjih ke-25 yang mewajibkan zakat profesi telah ditanfidzkan oleh Pimpinan Pusat Muhammadiyah. Dalam persyarikatan Muhammadiyah, segala keputusan yang diambil dalam berbagai forum pengambilan keputusan (muktamar, tanwir, munas dan sebagainya), dinyatakan berlaku sejak ditanfidzkan. Keputusan yang sudah ditanfidzkan merupakan pedoman dan rujukan dalam mengambil kebijakan dan pelaksanaan kegiatan bagi pimpinan persyarikatan di semua tingkatan, pimpinan organisasi otonom serta seluruh pimpinan amal usaha persyarikatan.

Terkait dengan keputusan Munas Tarjih ke-25 yang mewajibkan zakat profesi, amal usaha Muhammadiyah di Kota Pontianak, yaitu sekolah, perguruan tinggi, klinik, yang 
juga mempekerjakan berbagai profesi, berkewajiban untuk mengimplementasikannya. Bagaimana kebijakan persyarikatan dan amal usaha Muhammadiyah di Kota Pontianak dalam mengimplementasikan keputusan Munas Tarjih tentang zakat profesi, merupakan permasalahan yang perlu dikaji. Oleh karena itu, peneliti mengkajinya sebagai salah satu bentuk sumbangsih akademik dalam memajukan pranata hukum Islam di Indonesia.

\section{Metode}

Merujuk pada studi ilmu-ilmu keislaman, penelitian tentang zakat dapat dimasukkan dalam bidang penelitian hukum Islam dan pranata sosial. Hal itu sejalan dengan pernyataan Bisri yang menyatakan bahwa ada sebelas wilayah penelitian hukum Islam dan pranata sosial, yaitu pranata peribadatan, kekerabatan, pendidikan, penyiaran, keilmuan, hukum, politik, ekonomi, kesehatan, perawatan, dan kesenian (Bisri 2004). Dilihat dari cakupan wilayah penelitian hukum Islam tersebut maka penelitian tentang zakat dapat dimasukkan ke dalam kategori pranata peribadatan sekaligus juga ekonomi.

Berdasarkan deskripsi tersebut, maka jenis penelitian yang digunakan pada riset ini adalah penelitian lapangan (fied research) dengan menggunakan metode penelitian kualitatif. Adapun subjek penelitian adalah Amal Usaha Muhammadiyah di Kota Pontianak dan objek penelitian adalah implementasi keputusan Munas Tarjih tentang zakat profesi.

Sumber data dalam penelitian ini terdiri dari sumber data primer dan sumber data sekunder.Sumber data primer dari penelitian ini adalah hasil wawacara dengan pejabat atau petugas yang secara kelembagaan atau personal bertanggung jawab dalam mengelola zakat profesi, baik di Amal Usaha Muhammadiyah maupun di majelis dan lembaga terkait. Sumber data dimaksud adalah: (1). H. Nilwani Hamid, S.ag., M.Pd. Wakil Ketua Pimpinan Wilayah Muhammadiyah Kalimantan Barat, Pembina bidang zakat, dan dakwah khusus, (2) Ir. Untad Darmawan, M.Si., Wakil Bendahara PWM Kalbar dan mantan Kepala Biro Administrasi Umum dan Keuangan (BAUK) Universitas Muhammadiyah Pontianak, periode 1990 - 1998, (3) Drs. H. Slamet Rianto, M.Pd., Kela SD Muhammadiyah 2 dan SMP Muhammadiyah 1 Pontianak sekaligus sebagai Ketua Pimpinan Daerah Muhammadiyah Kota Pontianak, periode 2010-02015 dan priode 2015- 2020, (4) Ismail Syailillah, S.E., Ketua Lembaga Amil Zakat Infak dan Sedakah (Laizmu) Wilayah Kalimantan Barat, (5) Hariansyah, S.HI., M.Pd. Wakil Rektor I Universitas Muhammadiyah Pontianak periode 2017-2021 dan mantan Kepala Uniit Al Islam dan Kemuhammadiyahan Universitas Muhammadiyah Pontianak, (6) Deni Hamdani, S.Pdl, Kepala SMA Muhammadiyah I Pontianak. Keenam informan ini memahami kebijakan dan praktik penghimpunan zakat profesi dan infak pada Amal Usaha Muhammadiyah Kalimantan Barat.

Sumber data lainnya adalah, dokumen yang terkait dengan kebijakan persyarikatan Muhammadiyah mengenai imlementasi Keputusan Munas Tarjih tentang zakat profesi, 
baik tingkat pusat, wilayah, dan daerah serta kebijakan yang diambil oleh amal usaha Muhammadiyah di Kota Pontianak. Sumber data sekunder adalah literatur yang terkait dengan zakat profesi seperti buku Hukum Zakat oleh Yusuf Qardawi.

Metode pengumpulan data pada penelitian ini adalah wawancara dan dokumentasi. Wawancara yang digunakan dalam penelitian ini adalah wawancara tidak terstruktur. Pedoman wawncara yang digunakan hanya berupa garis-garis besar permasalahan yang akan ditanyakan (Sugiyono 2015). Dalam penelitian ini peneliti mewawancarai Pimpinan Wilayah Muhammadiyah Kalimantan Barat dan Pimpinan Daerah Muhammadiyah Kota Pontianak untuk memperoleh informasi mengenai kebijakan persyarikatan dalam mengimlementasikan Keputusan Munas Tarjih tentang zakat profesi. Wawancara juga dilakukan terhadap beberapa pimpinan Amal Usaha Muhammadiyah di Kota Pontianak sebagai informan kunci yang mengetahui implementasi keputusan Munas Tarjih tentang zakat profesi di Amal Usaha Muhammadiyah. Mengingat Amal Usaha Muhammadiyah di Kota Pontianak yang lebih banyak adalah di bidang pendidikan, dari sekolah dasar sampai perguruan tinggi maka informan ini juga mewakili unsur tersebut.

Metode yang kedua adalah dokumentasi. Dalam hal ini dokumen yang peneliti gunakan adalah dokumen cetak berupa Surat Keputusan dan Surat Edaran (instruksi) pimpinan persyarikatan berkaitan dengan pengelolaan zakat dan infak di amal usaha Muhammadiyah. Di samping itu digunakan pula dokumen noncetak (file) dengan cara mengunduh data-data dari situs-situs resmi persyarikatan Muhammadiyah, khususnya dari Majelis Tarjih dan Tajdid, serta dari Lazismu.

Melalui analisis data secara kualitatif, peneliti mengolah dan menganalisis data dalam penelitian ini dengan menggunakan pendekatan induktif, yakni peneliti mengumpulkan data yang bersifat khusus, kemudian diambil kesimpulan yang bersifat umum. Artinya, peneliti mengumpulkan data dari informan dengan teknik wawancara mendalam yang berkaitan dengan implementasi Keputusan Munas Tarjih tentang zakat profesi pada Amal Usaha Muhammadiyah di Kota Pontianak, selanjutnya ditarik kesimpulan dari informasi tersebut.

\section{Hasil Penelitian dan Pembahasan}

Dalam persyarikatan Muhammadiyah, istilah amal usaha dimaksudkan sebagai segala usaha atau kegiatan yang ditujukan untuk mencapai tujuan Muhammadiyah sebagaimana tercantum dalam Anggaran Dasar organisasi ini, Pasal 6, "Maksud dan tujuan Muhammadiyah ialah menegakkan dan menjunjung tinggi Agama Islam sehingga terwujud masyarakat Islam yang sebenar-benarnya".

Di Kota Pontianak terdapat sejumlah amal usaha, baik bidang pendidikan, kesehatan, sosial, maupun ekonomi. Di bidang pendidikan ada sekolah, (sekolah dasar, sekolah menengah pertama, sekolah menengah atas, sekolah menengah kejuruan) dan perguruan

al-ạ̣kām Vol. 4, Nomor 1, 2019 
tinggi. Di bidang sosial ada ada panti asuhan, di bidang kesehatan ada klinik, dan di bidang ekonomi ada travel.

Meskipun berlokasi di Kota Pontianak, penanggung jawab atau penyelenggara amal usaha tersebut tidak sama, ada yang diselenggarakan oleh pimpinan Muhammadiyah, ada yang diselenggarakan oleh pimpinan wilayah, dan ada yang diselenggarakan oleh pimpinan pusat, baik Muhammadiyah maupun Aisyiyah yang meliputi bidang pendidikan, sosial, dan kesehatan. Di bidang pendidikan terdiri dari tiga SD, tiga SMP, dua SMA, dua SMK, dan tiga perguruan tinggi. Di bidang sosial terdiri dari Panti Asuhan Tunas Melati dan Panti Asuhan Tunas Harapan. Sedangkan di bidang kesehatan terdapat Klinik Kitamura.

Meskipun berdomisili di Kota Pontianak, amal usaha tersebut penyelenggaranya berbeda jenjang organisasinya. Adanya perbedaan penyelenggara amal usaha, di samping karena mengikuti ketentuan yang sudah diatur dalam kaidah (pedoman) penyelenggaraannya, khususnya sekolah adalah karena hasil rekomendasi Musyawarah Wilayah Muhammadiyah Tahun 1986 yang mengusulkan agar SD Muhammadiyah 2 Pontianak, SMP Muhammadiyah 1 Pontianak, SMA Muhammadiyah 1 Pontianak, dan SMK Muhammadiyah 1 Pontianak ditetapkan sebagai sekolah percontohan (pilot project) untuk sekolah-sekolah Muhammadiyah di Kalimantan Barat. Oleh karena itu, pengelolaannya di bawah Pimpinan Wilayah Muhammadiyah Kalimantan Barat, meskipun sebenarnya menurut Kaidah Pendidikan Dasar dan Menengah berada di bawah Pimpinan Daerah untuk SMP dan SMA dan di bawah Pimpinan Cabang untuk SD. Hal ini dimaksudkan untuk mendorong percepatan peningkatan mutu sekolah. Sementara itu, Perguruan tinggi penyelenggaranya adalah Pimpinan Pusat yaitu Majelis Pendidikan Tinggi dan Pengembangan, baik Muhammadiyah maupun Aisyiyah. Untuk melakukan pembinaan dan pengawasan dibentuk institusi yang dinamakan Badan Pembina Harian (BPH).

Pada amal usaha Muhammadiyah di Kota Pontianak dipekerjakan pegawai dengan sebutan sesuai dengan profesinya. Status kepegawaiannya juga beragam. Misalnya di amal usaha bidang pendidikan, ada guru atau dosen pegawai negeri yang dipekerjakan di sekolah atau perguruan tinggi Muhammadiyah, ada guru atau dosen, atau pegawai administratif yang diangkat oleh Muhammadiyah yang disebut guru atau dosen atau pegawai administratif tetap. Ada pula guru atau dosen atau pegawai administratif tidak tetap (honorer/kontrak). Untuk guru atau dosen tidak tetap ini umumnya mereka adalah guru atau dosen pegawai negeri yang memiliki tugas pokok di sekolah atau perguruan tinggi negeri.

Menyangkut implementasi hasil Munas Tarjih tentang zakat profesi di amal usaha Muhammadiyah di Kota Pontianak, kebijakan persyarikatan (Pimpinan Wilayah Muhammadiyah Kalimantan Barat) awalnya bersifat meneruskan tanfidz PP Muhammadiyah kepada PDM dan majelis terkait, karena jauh sebelum diputuskan wajibnya zakat profesi, di lingkungan amal usaha Muhammadiyah sudah diberlakukan pemotongan gaji/honor 
pegawai/guru sebesar $2,5 \%$ sebagai zakat/infak. Pemotongan itu diberlakukan secara umum dalam artian tidak berdasar pada besarnya gaji atau honor. Demikian pula tidak dibedakan status kepegawaian pegawai (guru/dosen), baik pegawai tetap yang diangkat oleh persyarikatan maupun pegawai honor, termasuk pegawai kontrak. Kebijakan itu diambil sebagai bagian dari dakwah/pembinaan kepada pegawai dalam mengamalkan perintah agama, khususnya kewajiban berzakat dan bagi yang gajinya belum mencapai perhitungan nisab sebagai dorongan untuk berinfak dan bersedekah.

Kebijakan khusus lainnya yang dikeluarkan oleh Pimpinan Wilayah Muhammadiyah Kalimantan Barat adalah mengeluarkan instruksi tentang pengelolaan zakat profesi yang dihimpun oleh Amal Usaha Muhammadiyah. Instruksi Nomor 133/Inst/IIIOK/2014, tanggal 13 Sya'ban 1435 H/13 Juni 2014 M, itu berisi hal-hal sebagai berikut:

a. Seluruh pengelola Amal Usaha Muhammadiyah agar mengkoordinir penghimpunan zakat, infak, dan shadaqah dari karyawan, guru, dosen, tenaga medis, dan lain sebagainya di lingkungan AUM.

b. Setelah terhimpun dana tersebutagar disetor ke Lembaga Amil Zakat, Infak, dan Shadaqah Muhammadiyah Kalimantan Barat melalui rekening Bank Syariah Mandiri, atas nama Lazis Muhammadiyah Kalimantan Barat Nomor 3980001078 atau diambil oleh petugas dari Lazis PWM Kalimantan Barat.

c. Pengelola Lazis Muhammadiyah Kalimantan Barat agar menelola zakat, infak, dan shadaqah sesuai dengan ketentuan syariat.

d. Pengelola Lazis Muhammadiyah Kalimantan Barat agar membuat laporan untuk disampaikan kepada Pimpinan Wilayah Muhammadiyah Kalimantan Barat dan ditembuskan kepada masing-masing pengelola AUM.

Kebijakan ini dikeluarkan dalam rangka meningkatkan mutu pengelolaan zakat, infak, dan shadaqah di lingkungan persyarikatan Muhammadiyah Kalimantan Barat.Hal itu sejalan pula dengan semangat dan maksud dari Lazismu sebagaimana tercermin dari panduan tentang Lazismu yang dikeluarkan oleh Pimpinan Pusat Muhammadiyah.

Meskipun telah dikeluarkan instruksi kepada AUM untuk menyerahkan zakat, infak, dan sedekah yang dihimpunnya kepada Lazismu, menurut Nilwani Hamid, hal itu tidak ditekankan bagi AUM bidang sosial (panti asuhan) karena di panti asuhan jumlah pengasuh yang digaji sedikit sedangkan pengelola tidak digaji. Penjelasan seperti itu juga dibenarkan oleh Slamet Rianto dalam kapasitasnya sebagai Ketua Pimpinan Daerah Muhammadiyah Kota Pontianak. Bahkan sekolah-sekolah Muhammadiyah yang kondisi keuangannya masih minim, menjadi sasaran pendistribusian zakat, infak, dan sedekah dari AUM yang lainnya. Meskipun begitu, guru atau pegawai administratif yang menerima gaji dari sekolah tetap dipotong $2,5 \%$, tapi penyalurannya di lingkungan internal sekolah.

al-ạ̣kām Vol. 4, Nomor 1, 2019 
Berdasarkan penjelasan Slamet Rianto, zakat profesi yang dihimpun oleh AUM pengelolaannya bervariasi antara AUM satu dengan lainnya dan mengalami perubahan dan perkembangan dari waktu ke waktu. Namun, kesamaannya adalah bahwa zakat profesi itu dipotong langsung dari gaji/honor dan tercantum dalam kolom daftar gaji. Pada awalnya, zakat profesi yang sudah terhimpun didistribusikan oleh pimpinan AUM untuk (a) beasiswa murid yang tidak mampu dari sekolah tersebut (b) disalurkan kepada fakir/miskin melalui guru/karyawan yang menyampaikan datanya kepada kepala sekolah dan setelah dinilai layak ditindaklanjuti dengan pembegian zakat dimaksud, (c) disalurkan kepada pihak-pihak yang mengajukan permohonan kepada sekolah,(d) mendukung kegiatan organisasi otonom Muhammadiyah yang dipandang relevan.

Setelah berdirinya Lembaga Amil Zakat, sebagian zakat profesi yang dihimpun oleh AUM disetor ke Lazismu dan sebagian lagi disalurkan oleh sekolah dengan pola sebagaimana sebelumnya. Dalam perkembangan selanjutnya, berdasarkan instruksi Pimpinan Wilayah Muhammadiyah Kalimantan Barat Nomor133/Inst/IIIOK/2014, zakat profesi yang dihimpun oleh sekolah disetorkan kepada Lazismu Wilayah Kalimantan Barat. Namun, sekolah masih dapat menyalurkan kepada lingkungan internal, baik siswa yang menurut pengamatan masih perlu dibantu dengan cara mengajukan kepada Lazismu atau bila mendesak langsung menyalurkannya kemudian mengkoordinasikannya kepada Lazismu.

Implementasi Keputusan Munas Tarjih tentang Zakat Profesi di SMA Muhammadiyah 1 Pontianak sebagai sekolah percontohan di lingkungan Pimpinan Wilayah Muhammadiyah Kalimantan Barat juga berjalan seperti AUM lainnya. Deni Hamdani menjelaskan bahwa hasil zakat, infak, dan sedekah yang dihimpun itu disalurkan sebagian besar untuk bantuan beasiswa kepada siswa yang kurang mampu di SMA Muhammadiyah 1 Pontianak. Hal itu dilakukan karena masih cukup banyak siswa di sekolah ini yang tergolong kurang mampu. Biasanya orang tua yang kurang mampu mengajukan permohonan kepada sekolah untuk keringanan biaya SPP dan lain-lain. Selanjutnya sekolah meneliti kelayakannya dan bila dipandang layak dibantu diberikan keringanan bahkan ada yang dibebaskan.

Terkait dengan adanya instruksi dari PWM Kalbar agar AUM menyetorkan hasil zakat, infak, dan sedekah yang dipotong dari gaji guru dan karyawan, SMAM 1 Pontianak memang belum dapat memenuhinya karena dana tersebut terserap seluruhnya di internal sekolah ini. Dana yang disetor ke Lazismu adalah dana dari infak umum dari siswa yang dikumpulkan secara insidental yang biasanya disosialisasikan oleh Lazismu. Menyangkut pelaporan, SMAM 1 Pontianak secara periodik melaporkan pengelolaan zakat ini kepada Majelis Dikdasmen PWM Kalbar dan terakhir ini juga kepada Lazismu Wilayah Kalbar.

Dalam kapasitasnya sebagai Ketua Pimpinan Daerah Muhammadiyah Kota Pontianak, Slamet Rianto menjelaskan bahwa di AUM Kota Pontianak kebijakan pemotongan gaji dan honor sebesar 2,5\% juga diberlakukan, termasuk di AUM yang gaji/honornya minim 
sekalipun. Pengelolaannya hampir sama dengan sekolah yang dibina oleh wilayah. Hanya saja, sejak adanya instruksi Pimpinan Wilayah Muhammadiyah Kalimantan Barat agar AUM menyetorkan hasil zakat, infak, dan sedekah yang dihimpun dari pemotongan gaji guru dan karyawan diserahkan kepada Lazismu, untuk AUM yang di bawah pembinaan PDM Kota Pontianak diserahkan kepada Lazismu Kota Pontianak. Hal ini sesuai dengan hasil koordinasi antara Lazismu Wilayah dengan Lazismu Daerah.

Menyangkut pertanggungjawaban pengelolaan zakat profesi di AUM, Slamet Rianto menjelaskan bahwa pada mulanya dilaporkan secara periodik kepada Majelis Dikdasmen yang membawahi sekolah, selanjutnya dipertanggungjawabkan ketika sekolah (AUM) mendapat pembinaan (diperiksa) oleh Lembaga Pembinaan dan Pemeriksaan Keuangan Muhammadiyah (LP2KM).

Kebijakan pemotongan gaji pegawai di jenjang persekolahan Muhammadiyah Kota Pontianak juga diberlakukan di Universitas Muhammadiyah Pontianak. Berdasarkan informasi dari Untad Darmawan, selaku mantan Kepala Biro Administrasi Umum dan Keuangan periode 1990 s.d.1998 (yang juga salah satu anggota Tim Pendiri UMP), kebijakan pemotongan itu sudah berlaku sejak UMP didirikan. Melalui sosialisasi yang dilakukan terhadap dosen dan karyawan kebijakan itu diterina dengan baik, bahkan banyak dosen luar biasa dan pejabat struktural yang menyerahkan seluruh gajinya sebagai infak kepada UMP mengingat pada periode awal keadaan keuangan perguruan tinggi ini masih minim. Dana zakat, infak, dan sedekah yang terkumpul pada awalnya sebagian besar digunakan untuk menanggulangi biaya operasional. Dalam perkembangan selanjutnya ada juga untuk bantuan beasiswa kepada mahasiswa yang kurang mampu dari kalangan internal UMP terutama mahasiswa yang berasal dari Panti Asuhan Muhammadiyah/Aisyiyah (Wawancara tanggal 16 Oktober 2017).

Menurut Heriansyah, Wakil Rektor 1 UMP, periode 2016-2020, kebijakan pemotongan gaji 2,5\% sebagai zakat, infak, dan sedekah tersebut masih berlaku (wawancara tanggal 19 Oktober 2017). Hanya saja, penyalurannya sudah lebih luas. Di samping untuk beasiswa bagi Mahasiswa UMP yang kurang mampu, juga disalurkan kepada pihak-pihak yang mengajukan permohonan yang setelah diteliti oleh Unit Al Islam dan Kemuhammadiyahan dipandang relevan untuk dibantu dengan dana zakat. Ada juga yang dipakai untuk mendukung kegiatan sosial yang dilakukan oleh Unit Kegiatan Mahasiswa UMP. Setelah adanya instruksi PWM Kalbar tentang penyerahanan zakat dari AUM kepada Lazismu maka pihak UMP setelah berkoordinasi dengan Lazismu, menyerahkan sebagian kepada Lazismu sedangkan sebagian lainnya masih dikelola dan didistrubusikan oleh UMP.

al-ạ̣kām Vol. 4, Nomor 1, 2019 
Menyangkut pelaporan, selama ini dilakukan oleh Bagian Keuangan kepada Rektor UMP yang selanjutnya dilaporkan kepada Badan Pembina Harian (BPH) UMP. Setelah adanya kewajiban menyetorkan dana zakat kepada Lazismu maka menjadi tanggung jawab Lazismu yang menyampaikan laporan kepada Pimpinan Wilayah Muhammadiyah Kalimantan Barat.

Tata kelola zakat profesi yang sudah disetorkan AUM kepada Lazismu dilakukan oleh Lazismu berdasarkan kaidah atau ketentuan yang berlaku di Lazismu, tapi tetap memperhatikan kondisi di daerah. Menurut Ismail Syailillah, Ketua Lazismu Kalbar (wawancara tanggal 12 Oktober 2017) Lazismu dalam mengemban amanah PWM Kalimantan Barat, terlebih dahulu melakukan koordinasi dengan pimpinan AUM dengan cara beraudiensi dengan mereka untuk menyamakan persepsi tentang pengelolaan zakat profesi yang dihimpun oleh AUM. Setelah koordinasi dan terjadi kesamaan persepsi, secara bertahap AUM menyetorkan zakat profesi ke Lazismu. Sampai saat ini, AUM yang sudah menyetor sebagian zakat profesi yang dihimpunnya kepada Lazismu Wilayah adalah SD Muhammadiyah 2, SMP Muhammadiyah 1, SMK Muhammadiyah 1, Universitas Muhammadiyah Pontianak, Sekolah Tinggi Ilmu Keperawatan (STIK) Muhammadiyah Pontianak, dan Akademi Kebidanan Aisyiyah Pontianak. Jadi, hanya SMA Muhammadiyah 1 Pontianak yang belum menyetorkan tetapi sudah menyampaikan informasi tentang penerimaan dan pendistrubusian zakat propesi yang mereka himpun.

Mengenai tata kelola zakat di Lazismu, Ismail Syailillah menjelaskan “Kami mengelola zakat, infak, dan sedekah yang dihimpun oleh Lazismu mengikuti panduan yang dikeluarkan oleh Lazismu Pusat. Misalnya, untuk penyaluran terlebih dahulu dilakukan penelitian terhadap mustahik, baik yang datang sendiri ke Lazismu maupun atas usul organisasi atau lembaga yang mengajukannya ke Lazismu. Hal itu berlaku untuk semua zakat yang dihimpun dari berbagai sumber. Namun, khusus untuk dana zakat profesi yang berasal dari AUM, di antaranya adalah berdasarkan rekomendasi dari AUM yang sebelumnya menyalurkan sebagian zakat ini kepada pihak-pihak tersebut, umumnya merupakan AUM bidang sosial seperti Panti Asuhan di Rasau Jaya. Ada juga AUM di bidang pendidikan yang kondisi keuangannya masih minim seperti SD Muhammadiyah Rasau Jaya dan SD Muhammadiyah 3 Pontianak yang beralamat di Gang Mariana."

Menyangkut pelaporan, lebih lanjut Ismail Syailillah menjelaskan bahwa Lazismu Kalbar secara periodik menyampaikan laporan ke Lazismu Pusat dengan tembusan kepada Pimpinan Wilayah Muhammadiyah Kalbar, namun tidak dipisahkan zakat profesi yang bersumber dari AUM.

Pemotongan gaji pegawai (guru, dosen) sebesar 2,5\% sudah berlangsung sebelum lahirnya keputusan Munas Tarjih tentang wajibnya zakat profesi. Oleh karena itu, ketika persyarikatan, melalui PWM dan PDM meneruskan tandidz keputusan Munas Tarjih tersebut, tidak ada kendala yang berarti dalam implementasinya. Artinya, kalangan 
pegawai sudah memahami hal itu. Bahkan untuk pegawai yang baru pun mereka sudah menerima itu sebagai sistem yang berlaku di Muhammadiyah. Apalagi mereka juga mendapat pembinaan di bidang Al Islam dan Kemuhammadiyahan sehingga memahaminya sebagai kewajiban. Sejauh ini tidak pernah terdengar ada pegawai yang keberatan. Kendala dalam pendistribusiannya juga tidak ada karena banyak pihak yang meminta zakat ke AUM. Hanya saja pada saat AUM yang mendistribusikan, penelitian terhadap kelayakan mustahik disadari kurang mendalam. Biasanya diserahkan kepada guru atau karyawan yang merekomendasikan/mengusulkan. Namun, setelah diserahkan kepada Lazismu, tentu hal itu dilakukan sesuai Standar Operasional Prosedur di Lazismu.

Implementasi Keputusan Munas Tarjih tentang zakat profesi di Amal Usaha Muhammadiyah di Kota Pontianak diawali dengan kebijakan persyarikatan (Pimpinan Wilayah Muhammadiyah Kalimantran Barat dan Pimpinan Daerah Muhammadiyah Kota Pontianak) yang meneruskan Tanfidz Keputusan Munas Tarjih tentangt Zakat Profesi kepada AUM di Kota Pontianak sekaligus menegtaskan agar melenjutkan kebijakan pemotongan gaji/honor pegawai sebagai zakat/infak. Kebijakan ini telah sesuai dengan kedudukan dan fngsi persyarikatan sebagai badan hukum penyelenggara amal usaha Muhammadiyah Pemotongan secara langsung gaji pegawai di Amal Usaha Muhammadiyah berlaku untuk semua, baik itu pegawai tetap, pegawai honorer maupun pegawai kontrak. Demikian juga tidak dilihat dari besaran gaji pegawai, apakah sudah mencapai nisab wajib zakat atau belum. Hal itu sesuai dengan istilah yag dipakai dalam pemotongan gaji tersebut yakni zakat, infak, dan shadaqah sehingga dipahami bagi yang gajinya sudah mencapai nisab wajib zakat berarti yang dipotong adalah zakat profesi sedangkan bagi yang gajinya belum mencapai nisab wajib zakat dianggap sebagai infak. Untuk mendukung kebijakan itu pimpinan persyarikatan di setiap tingkatan melalui majelis terkait memberikan pembinaan kepada pegawai (guru, dosen) tentang pentingnya zakat,infak, dan shadaqah sehingga kebijakan tersebut diterima dengan baik oleh pegawai. Bahkan menumbuhkan semangat berinfak sebagaimana tercermin dari adanya infak-infak yang dipungut secdara insidentil di Amal Usaha Muhammadiyah. Pada tingkat pimpinan amal usaha adanya kebijakan pemotongan gaji sebagai zakat/infak tersebut dijadikan juga pertimbangan ketika akan melakukan perbaikan penghasilan sesuai dengan kemampuan AUM. Artinya, kepantasan gaji/honor yang bakal diterima pegawai adalah gaji/honor bersih (Hasil wawancara dengan Wakil Ketua PWM dan Ketua PDM Kota Pontianak).

Kebijakan yang dikeluartkan oleh Pimpinan Wilayah Kaliman Barat yang telah menginstruksikan agar zakat, infak dan shadaqah yang dihimpun oleh AUM di Kota Pontianak diserahkan pengelolaannya kepada Lazismu dimaksudkan untuk menempatkan Lazismu sesuai dengan dengan fungsi dan kedudukannya. Dengan terhimpunnya zakat profesi serta infak dan shadaqah ini pada Lazismu akan diketahui potensi yang dimiliki sehingga dapat disusun program pendayagunaan yang lebih tepat sasaran dalam artian

al-aḥkām vol. 4, Nomor 1, 2019 
sesuai dengan tuntunan syariah. Kebijakan tersebut diikuti pula dengan penegasan agar Lazismu mengelolanya sesuai dengan Pedoman Pengelolaan Lazismu yang dikeluarkan oleh Lazismu Pusat. Instruksi yang dikeluarkan oleh PWM Kalimantan Barat itu juga berdampak pada semakin aktifnya Lazismu menjalankan fungsinya karena telah memiliki basis garapan yang jelas. Dengan kata lain penghimpunan dana zakat profesi dari AUM di Kota Pontianak kepada Lazismu telah menjadi pendorong Lazismu memperluas jaringan dan mengenalkan keberadaan Lazismu karena ketika capaian penggalangan dana itu dipublikasikan telah berhasil menumbuhkan kepercayaan masyarakat kepada Lazismu.

Tatakelola kebijakan persyarikatan tentang zakat profesi pada amal usaha Muhammadiyah di Kota Pontianak pada dasarnya bervariasi dan mengalami perkembangan dari waktu ke waktu. Secara garis besar dapat dikelompokkan sebagai berikut.

a. Ada AUM yang pada awalnya mengelola zakat profesi dan infak pegawai yang dihimpunnya untuk disalurkan sebagai bantuan (beasiswa) bagi mahasiswa dari AUM itu sendiri. Hal itu karena dana zakat dan infak yang diterima masih relatif kecil sementara kondisi keuangan AUM tersebut juga masih terbatas. Namun dalam perkembangan selanjutnya ketika jumlah zakat dan infak yang diterima semakin besar, AUM tersebut sudah dapat mendistribusikan hasil zakat dan infak kepada mustahik dari kalangan eksternal meskipun masih tetap ada dari kalangan internal. Hal ini terjadi di Universitas Muhammadiyah Pontianak. Pelaporan dalam pengelolaan pola ini pada awalnya masih terbatas di internal AUM itu sendiri dan secara bertahap sudah ke eksternal (melibatkan Lazismu).

b. Ada AUM yang sejak awal dilakukannya pemotongan gaji pegawai sebagai zakat/ infak telah menyalurkannya kepada mustahik dari kalangan eksternal AUM tersebut melalui pegawai (guru/dosen) atau pihak-pihak lain yang mengajukan permohonan. Hal itu dimungkinkan karena di AUM itu sendiri siwa/mahasiswa yang tergolong kurang mampu jumlahnya kecil sedangkan jumlah zakat dan infak yang diterima sudah agak banyak. Hal ini misalnya terjadi di SD Muhammadiyah 2 Pontianak, di Sekolah Tinggi Ilmu Keperawatan Muhammadiyah Pontianak, dan di Akademi Kebidanan Aisyiyah Pontianak. Pelaporan pada pola ini pada awalnya masih terbatas di internal AUM itu sendiri dan secara bertahap sudah ke ekternal (melibatkan Lazismu)

c. Ada AUM yang sejak dilakukannya kebijakan pemotongan gaji pegawai sebagai zakat, infak, dan shadaqah dan menggunakannya sebagai bantuan (beasiswa) bagi siswa di AUM itu sendiri. Hal itu karena cukup banyak siswa dari kalangan yang kurang mampu yang meminta keringanan pembayaran SPP sedangkan jumlah zakat/ infak yang dihimpun juga terbatas. Sementara itu, kondisi keuangan AUM masih terbatas sehingga belum dapat memberikan keringanan biaya kepada siswa. Hal 
ini terjadi di SMA Muhammadiyah 1 Pontianak, SMK Muhammadiyah dan sekolahsekolah di bawah pembinaan Pimpinan Daerah Muhammadiyah Kota Pontianak (SD Muhammadiyah 1 dan 2, SMP Muhammadiyah 2 dan 3 serta SMK Muhammadiyah 2 Pontianak). Pelaporan dalam pola ini masih terbatas pada internal AUM itu sendiri dan pimpinan persyarikatan di atasnya.

d. Sejak dikeluarkannya instruksi Pimpinan Wilayah Muhammadiyah Kalimantan Barat yang mewajibkan AUM menyerahkan hasil zakat, infak, dan shadaqah yang dihimpun dari pemotongan gaji pegawai, sebagian AUM di Kota Pontianak telah menyetorkan sebagian hasil zakat dan infak yang dihimpunnya kepada Lazismu sementara sebagian lainnya masih dikelola sendiri untuk disalurkan, baik di kalangan internal maupun eksternal. Pelaporan dengan pola ini sudah melibatkan Lazismu karena ketika menyetorkan zakat, infak, dan shadaqah kepada Lazismu sudah dinyatakan prosentase yang diserahkan dan prosentase yang dikelola sendiri. Namun, rician yang didistribusikan oleh AUM, ada pada AUM itu sendiri.

Berdasarkan pola-pola pengelolaan zakat/infak yang dilakukan di AUM Kota Pontianak tersebut terlihat pada priode awal dan pada sebagian AUM hingga saat ini, pendistribusian zakat masih didominasi untuk asnab fakir (fuqara) dan miskin (masaakiin) dan sebagian kecil juga asnab sabilillah, baik di internal AUM atau di kalangan eksternal. Demikian juga pendayagunaannya masih didominasi untuk kebutuhan mendesak yaitu biaya sekolah/kuliah dan mendukung kegiatan pengkaderan dan dakwah organisasi otonom Muhammadiyah.

Setelah dana zakat sebagian dikelola oleh Lazismu, pendistribusiannya meskipun masih dominan asnab fakir (fuqara) dan miskin (masaakin) dan sabilillah sudah pula menyentuh asnab lainnya seperti amiliin, muallafin, dan ibnu sabil. Namun untuk asnab miskin (masaakiin) pendayagunaannya tidak terbatas untuk kebutuhan mendesak tetapi sudah ada yang digunakan untuk modal usaha produktif, misalnya di bidang pertanian, industri kecil, dan usaha rumah tangga lainnya. Pelaporan untuk zakat dan infak yang dikelola oleh Lazismu sudah mengarah pada pengelolaan yang profesional, mengkuti pedoman pengelolaan Lazismu, juga dipublikasikan melalui media sosial (WA group Lazismu).

Zakat, infak, dan shadaqah yang bersumber dari Amal Usaha Muhammadiyah di Kota Pontianak telah menjadi stimulus yang cukup berarti bagi Lazismu sebagai modal dasar dalam melakukan mobilisasi penggalian potensi zakat, infak, dan sahadaqah baik di internal persyarikatan Muhammadiyah maupun ekternal. Tatakelola zakat yang disetorkan oleh AUM kepada Lazismu.

Kendala yang dihadapi dalam implementasi Keputusan Munas Tarjih tentang Zakat Profesi pada Amal Usaha Muhammadiyah di Kota Pontianak pada tataran penghimpunannya 
secara umum tidak ada. Hal itu disebabkan karena jauh sebelum ada keputusan Majelis Tajih tentang wajibnya zakat profesi, di lingkungan AUM di Kota Pontianak sudah diterapkan kebijakan pemotongan gaji pegawai sebagai zakat, infak, dan shadaqah. Hal itu sejalan dengan pandangan Prof. Asmuni yang peneliti kutip pada Kajian Teori, bahwa bulatnya keputusan Munas Tarjih ke-25 tentang zakat profesi antara lain karena di lingkungan Muhammadiyah, termasuk di AUM hal itu sudah diterapkan, berbeda dengan Muktamar Tarjih sebelumya yang belum menghasilkan kebulatan pendapat.

Kendala pada tataran pendistribusian zakat dan infak yakni pada awalnya belum terkoordinasi dengan baik, masing-masing amal usaha mendistribusikan berdasarkan pertimbangan internal, baik menyangkut asnab maupun sasarannya. Demikian juga pendayagunaannya masih dominan untuk kebutuhan mendesak (bersifat konsumtif).

Pada tataran pelaporan kendala yang dihadapi adalah pada awalnya hanya dilaporkan secara internal dalam institusi AUM itu sendiri, berikutnya ada yang dilaporkan kepada majelis yang membawahi AUM, seperti Majelis Dikdasmen yang membawahi sekolah. Setelah sebagian zakat dikelola oleh Lazismu, maka pelaporan dilakukan pula oleh Lazismu sesuai dengan pedoman pengelolaan zakat yang dikeluarkan oleh PP Muhammadiyah.

Aspek lain yang juga dapat dipandang sebagai kendala dari segi informasi adalah belum adanya pemilahan dari pegawai yang dipotong gajinya tersebut, apakah sebagai zakat profesi atau sebagai infak. Bila mengacu pada fatwa Majelis tentang zakat profesi sebagaimana diilustrasikan dalam kutipan berikut ini:

Contoh 1: Gaji profesi seorang pegawai Rp. 6.000.000,- / bulan.Setelah dipotong untuk membayar listrik, kebutuhan sekolah anak, dan konsumsi harian, ternyata masih tersisa Rp. 2.000.000,- Jika dikalkulasi dalam setahun ia mendapat Rp. 2.000.000,- x $12=\mathrm{Rp}$. 24.000.000,- maka ia tidak wajib mengeluarkan zakat karena tidak mencapai nishabnya (Rp. 42.500.000,- /tahun senilai nishab emas 85 gr), namun jika masih tersisa Rp. 3.600.000,x 12 = Rp. 43.200.000,- maka sudah mencapai nisab sehingga ia berhak mengeluarkan zakat sebesar 2,5 \% x Rp. 3.600.000,- = Rp.90.000,- jika dikeluarkan perbulan, atau bisa juga membayar satu kali tiap tahun sejumlah $12 \times$ Rp.90.000,- = Rp. 1.080.000,- (Tim Fatwa Majelis Tarjih dan Tajdid PP Muhammadiyah, 7 Jumadilawal 1433 H / 30 Maret 2012 M).

Mencermati ilustrasi dari Majelis Tarjih sebagaimana tertuang dalam fatwa tersebut terlihat bahwa wajibnya zakat profesi berlaku terhadap penghasilan bersih yang bila dikalikan dengan 12 bulan ( satu tahun) mencapai setara dengan nilai 85 gram emas. Sementara ini, amal usaha Muhammadiyah di Kota Pontianak belum mengklasifikasikan pemotongan gaji $2,5 \%$ sebagai zakat5, atau infak, atau shadaqah. 


\section{Kesimpulan}

Berdasarkan hasil kajian penelitian ini dapat dirumuskan beberapa kesimpulan.

1. Setelah ditanfidzkannya hasil Keputusan Munas Tarjih Muhammadiyah ke-25 yang menetapkan wajibnya zakat profesi, pimpinan persyarikatan membuat beberapa kebijakan dalam mengimplementasikan keputusan tersebut pada amal usaha Muhammadiyah di Kalimanatan Barat umumnya dan di Kota Pontianak. Pertama, meneruskan dan menguatkan kebijakan yang sudah berlangsung yakni memotong gaji pegawai sebesar $2,5 \%$ sebagai zakat, infak, atau shadaqah tanpa membedakan status kepegawaian (tetap, honorer, kontrak) dan tanpa membedakan besaran gaji pegawai. Kedua, untuk mengefektifkan pendayagunaan zakat profesi dan infak pegawai di AUM, persyarikatan (Pimpinan Wilayah Muhammadiyah Kalimantan Barat) mengeluarkan kebijakan mewajibkan AUM menyerahkan zakat profesi dan infak yang dihimpunnya pada Lembaga Amil Zakat Infak dan Sadakah Muhammadiyah (Lazismu) serta menugaskan Lazismu mengelolanya sesuai dengan pedoman pengelolaan yang telah dikeluarkan oleh Pimpinan Pusat Muhammadiyah.

2. Tata kelola zakat profesi pada Amal Usaha Muhammadiyah di Kota Pontianak bervariasi antara AUM satu dengan lainnya dan mengalami perubahan dari waktu ke waktu. Ada yang dikelola dan didistribusikan pada mustahik secara internal dari sejak awal berlakunya kebijakan pemotongan langsung 2,5\% dari gaji, ada yang secara bertahap juga didistribusikan kepada mustahik eksternal, dan ada yang sejak awal didistribusikan kepada mustahik ekternal, dengan jangkauan yang terbatas pada mustahik fakir dan miskin. Sejak dikeluarkannya kebijakan persyarikatan tentang kewajiban AUM menyerahkan zakat profesi dan infak pegawai kepada Lazismu, sebagian AUM sudah menyerahkan sebagian zakat profesi dan infak yang dihimpunnya kepada Lazismu. Pengelolaan zakat frofesi dan infak dari AUM oleh Lazismu dilakukan dengan pendistribusian yang lebih luas, termasuk muallaf, ibnu shabil, dan sabilillah. Untuk mustahik masyakin pemanfaatannya tidak hanya untuk kebutuhan mendesak tetapi juga sudah ada yang digunakan sebagai modal usaha produktif dengan bimbingan dan pembinaan dari Lazismu.

3. Pada tataran penghimpunan, secara umum tidak ada kendala dalam implementasi keputusan Munas Tarjih tentang Zakat profesi pada AUM di Kota Pontianak karena kebijakan pemotongan gaji $2,5 \%$ sebagai zakat, infak atau shadaqah sudah berlangsung sebelumnya dan sudah dipahami dan dihayati oleh pegawai. Pada tataran pengelolaan, pada awalnya belum terkoordinasi dengan baik karena masing-masing AUM menghimpun dan mendistribusikan sendiri sehingga persyarikatan belum mengetahui 
potensi zakat profesi yang ada pada AUM secara keseluruhan. Kendala pada taataran pengelolaan secara bertahap mulai teratasi ketika AUM sudah menyetorkan zakat, infak, dan shadaqah yang dihimpunnya kepada Lazismu.

\section{Daftar Pustaka}

Anis, Junus. 1972. "Asal Mula Diadakan Majelis Tarjih Dalam Muhammadiyah." Suara Muhammadiyah, 1972.

Bisri, Cik Hasan. 2004. Pilar-Pilar Penelitian Hukum Islam Dan Pranata Hukum Islam Dan Pranata Sosial. Jakarta: PT Raja Grafindo Persada.

Pimpinan Pusat Muhammadiyah. 1990. Berita Resmi Muhammadiyah, Nomor Khusus, Tanfidz Keputusan Muktamar Tarjih Muhammadiyah XXII. Malang: Pimpinan Pusat Muhammadiyah.

Sugiyono. 2015. Metode Penelitian Pendidikan, Pendekatan Kuantitatif, Kualitatif, Dan R\&D. Bandung: Alfabeta. 